\title{
Dynamics of dissolved oxygen inside salmon sea-cages with lice shielding skirts at two hydrographically different sites
}

\author{
Kristbjörg Edda Jónsdóttir ${ }^{1, *}$, Zsolt Volent ${ }^{2}$, Jo Arve Alfredsen ${ }^{1}$ \\ ${ }^{1}$ Norwegian University of Science and Technology, Department of Engineering Cybernetics, NO-7491 Trondheim, Norway \\ ${ }^{2}$ SINTEF Ocean, NO-7465 Trondheim, Norway
}

\begin{abstract}
Shielding skirts are widely used as a non-invasive preventive measure against salmon lice Lepeophtheirus salmonis infestations on Atlantic salmon Salmo salar in sea-cages. Low levels of dissolved oxygen (DO) are reported from some sites, but not others. This disparity is usually explained by local variations in current flow and hydrography. The aim of the present study was to investigate these local variations through vertical mapping of DO and hydrography at 2 hydrographically different sites equipped with shielding skirts. The 2 sites chosen, Fornes and Soløya, are in northern Norway and are equipped with a permeable and a non-permeable skirt, respectively. Over a period of $3 \mathrm{~d}$, current speed and direction were recorded outside the cage, while DO and hydrography were measured both inside and outside the cage, above and below the skirt. At Fornes, the DO inside the cage varied throughout the study period, while DO outside remained stable. The variation in DO inside the cage co-occurred with variations in strength and depth of a present pycnocline that broke down during the study period. At Soløya, DO levels were high throughout the study, and there was no gradient in salinity, temperature or density, indicating good vertical mixing. These data illustrate how the interaction between skirts and local conditions can influence the temporal and spatial variations of DO inside shielded cages and highlight the importance of studying local current conditions and hydrography when applying shielding skirts.
\end{abstract}

KEY WORDS: Lice shielding skirts - Dissolved oxygen · Pycnocline - Current flow pattern · Atlantic salmon $\cdot$ Salmon lice $\cdot$ Sea-cage environment

\section{INTRODUCTION}

Shielding skirts are widely used in Norway as a noninvasive preventive measure to reduce salmon lice Lepeophtheirus salmonis infestations on Atlantic salmon Salmo salar L. in sea-cages. Shielding skirts are a form of barrier technology that attempts to keep the infective copepodids out of the cage by rerouting the upper water column around the cage, which has a higher lice density than the deeper levels due to the preferred swimming depth of the louse (i.e. Huse \& Holm 1993, Heuch et al. 1995, Hevrøy et al. 2003, Oppedal et al. 2017, Geitung et al. 2019, Barrett et al. 2020).

\footnotetext{
${ }^{*}$ Corresponding author: kristbjorg.jonsdottir@ntnu.no
}

The effect of shielding skirts on lice infestation is varied, with some studies finding that skirts reduce lice infestations (Næs et al. 2012, Grøntvedt et al. 2018, Stien et al. 2018, Bui et al. 2020), whereas others find that at certain sites, skirts have little to no effect (Grøntvedt \& Kristoffersen 2015, Lien et al. 2015, Grøntvedt et al. 2018). Shielding skirts also affect the environment inside the cage, particularly the dissolved oxygen (DO) concentration (Oldham et al. 2017). Low DO and cyclic hypoxia inside fish cages reduce feed intake and specific growth rates (Remen et al. 2014), while moderate hypoxia can significantly reduce aerobic capacity and swimming

() The authors 2020. Open Access under Creative Commons by Attribution Licence. Use, distribution and reproduction are unrestricted. Authors and original publication must be credited. 
performance (Oldham et al. 2019). Higher water temperature increases the DO demand of Atlantic salmon (Remen et al. 2013, 2016), and this demand is mainly met by physical transport of sufficient amounts of oxygen-rich water through the cage (Wildish et al. 1993, Johansson et al. 2006). As the skirt diverts the flow around the cage, the natural exchange of water is disrupted and this can result in low DO levels (Stien et al. 2012). However, this effect does not occur at all sites, as some studies have reported sufficient DO inside cages with skirts (Næs et al. 2012, Stien et al. 2018).

One reason for these variations could be differences in the water exchange due to local flow patterns. Farm layout (Rasmussen et al. 2015), local topography (Klebert et al. 2013), cage structure (Klebert et al. 2015), bio-fouling (Gansel et al. 2015), presence of fish (Klebert et al. 2013, Gansel et al. 2014, Klebert \& Su 2020) and structures such as shielding skirts (Frank et al. 2015) all influence how the ocean currents flow through and around fish cages. Computational fluid dynamics (CFD) analyses of laminar current flow into a fish cage with a rigid shielding skirt show that part of the incoming current is pressed around the skirt, but a portion is pressed down along the skirt, underneath it and into the seacage (Lien \& Høy 2011, Lien et al. 2015). The deflection of the current underneath the shielding skirt and into the fish cage was observed in full-scale dye experiments (Frank et al. 2015). However, when repeating the dye experiment with similar ambient current conditions, the amount of dye entering the cage varied significantly (Frank et al. 2015). One variable that influences the current flow pattern, which could explain the observed variance, is density stratification (pycnocline) in the water column caused either by a salinity (halocline) or temperature (thermocline) gradient (Johansson et al. 2007, Gansel et al. 2014).

The density of seawater is predominantly determined by its salinity and temperature, hence a density gradient means that there is a gradient in salinity and/or temperature. Vertical stratification is known to inhibit vertical mixing in the water column (Imberger 2013), and thereby alter the current flow and the distribution of DO in the water column. Stratified sites show lower DO levels than homogeneous sites (Johansson et al. 2007), and haloclines are reported to influence the deflection of the ambient current around empty fish cages (Gansel et al. 2014). As vertical mixing is inhibited at the depth of the stratification, its vertical position is relevant. For instance, in Stien et al. (2012), the combination of relative low salinity and high temperature around the skirt depth is presented as an explanation for the low DO levels inside the fish cage. In addition, by influencing the vertical mixing, stratification can impact the effectiveness of the skirt as a preventive measure against lice (Geitung et al. 2019, Bui et al. 2020), as the vertical position of the salmon lice is influenced by environmental variables such as salinity (Bricknell et al. 2006, Crosbie et al. 2019) and temperature (Crosbie et al. 2020).

Local variations in DO inside fish cages and the varying efficiency of shielding skirts in lice prevention imply that hydrographical conditions at sites should be investigated in more detail. In the present study, 2 hydrographically different sites were monitored using similar equipment to exemplify the differences that can be observed in the field. DO levels and relative water density were measured inside and outside a fish cage at the 2 sites over a period of $3 \mathrm{~d}$ to study the dynamics of DO, current conditions and hydrography. The data provide important insight into how shielding skirts in combination with local conditions can influence the temporal and spatial variation of DO inside shielded cages.

\section{MATERIALS AND METHODS}

\subsection{Study sites}

The measurement campaigns were performed at the fish farms at Soløya $\left(68.004339^{\circ} \mathrm{N}, 13.181384^{\circ} \mathrm{E}\right)$ and Fornes $\left(68.410151^{\circ} \mathrm{N}, 15.435051^{\circ} \mathrm{E}\right)$, located in the Lofoten Islands, Norway (Fig. 1). To achieve continuous measurements unaffected by operational work and feeding, measurements were carried out between the late afternoon, or evening, and the morning. It should be noted that due to the latitudes of the sites, there was continuous daylight through the entire measurement period.

The first campaign was carried out from 21 to 24 May 2019 at Soløya, owned and operated by Ellingsen Seafood AS (Fig. 1). Data were collected over 2 nights between 21-22 May and 23-24 May. The second campaign was carried out at Fornes in Øksfjorden, owned and operated by Nordlaks Oppdrett AS (Fig. 1), with data recorded every night between 2 and 5 July 2019.

The Soløya farm consists of 12 cages in one row, aligned from north to south. Data were collected from the northernmost cage (Fig. 1), which had a circumference of $100 \mathrm{~m}$ and was equipped with a cylindrical net. The first $15 \mathrm{~m}$ of the cage were cylindrical and kept in place with 16 steel chain weights of $50 \mathrm{~kg}$, 

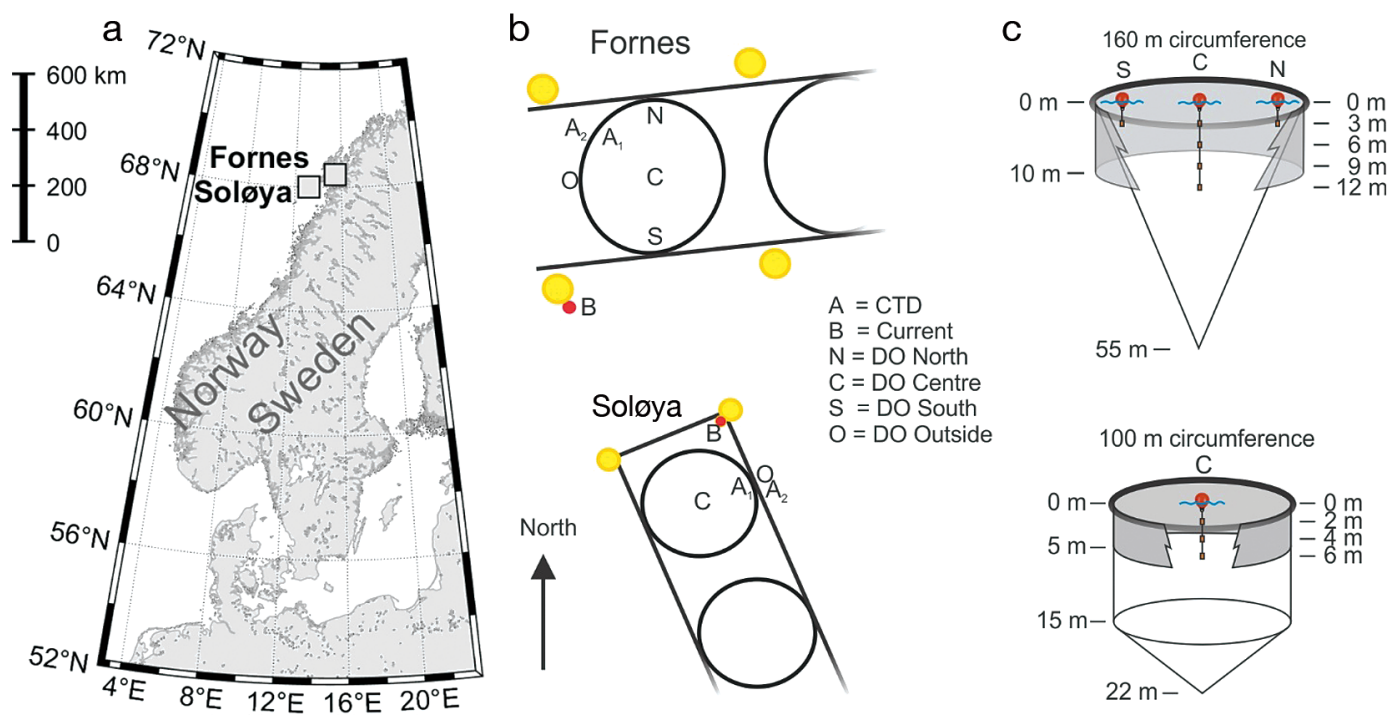

Fig. 1. (a) Locations of sites where measurement campaigns were carried out: Soløya in May 2019, and Fornes in July 2019. (b) Measurement positions of dissolved oxygen (DO), conductivity, temperature and depth (CTD) and current profiles at Fornes and Soløya. (c) Schematic diagram of the sea-cages. DO was measured at position O outside the cage at $3 \mathrm{~m}$ depth at Fornes and Soløya. DO was also measured in position $\mathrm{C}$ at 3, 6, 9 and $12 \mathrm{~m}$ at Fornes and at 2, 4 and $6 \mathrm{~m}$ at Soløya. At Fornes, DO was also measured at $3 \mathrm{~m}$ depth in positions $\mathrm{N}$ and $\mathrm{S}, 4 \mathrm{~m}$ from the floating collar. The CTD profiles were measured manually inside and outside the cage at positions $\mathrm{A}_{1}$ and $\mathrm{A}_{2}$, respectively. Current speed and direction profiles were measured at position B

each evenly distributed around the circumference of the cage. The bottom of the cage was formed as a cone from 15 to $22 \mathrm{~m}$ depth, with a $50 \mathrm{~kg}$ steel chain weight at the tip of the cone. The cage was equipped with a $5 \mathrm{~m}$ deep non-permeable tarpaulin shielding skirt (Botngaard), weighted with $4 \mathrm{~kg} \mathrm{~m}^{-1}$ around the bottom of the skirt (Fig. 1). The biomass in the cage during the experiments was $212 \mathrm{t}$, with 117500 fish of average weight of $1.8 \mathrm{~kg}$.

There were 9 cages at Fornes, also aligned in one row, but from west to east. Data were collected from the third westernmost cage (Fig. 1), which had a circumference of $160 \mathrm{~m}$ and was equipped with a conical net. The net was $55 \mathrm{~m}$ deep, with a concrete weight of 2.4 tonnes in water attached to the tip of the cone. The shielding skirt applied was a permeable canvas lice skirt (Norwegian Weather Protection) with a solidity of $51 \%$, mesh size of $350 \times$ $350 \mu \mathrm{m}$ and a depth of $10 \mathrm{~m}$ (Fig. 1). The skirt was weighted with $2 \mathrm{~kg} \mathrm{~m}^{-1}$ lead rope at the bottom. The biomass in the cage during the experiment was $750 \mathrm{t}$, with 191310 fish of average weight of $3.8 \mathrm{~kg}$.

\subsection{Measurements and sensors}

DO was measured every minute at both locations using PME MiniDO ${ }_{2} \mathrm{~T}$ oxygen sensors (Kem-En-Tec
Nordic). Due to its larger size, Fornes was equipped with 2 additional Aanderaa Optodes 4330 oxygen sensors (Aanderaa Data Instruments). At Soløya, DO was recorded in the cage centre at 2, 4 and $6 \mathrm{~m}$ depth, such that measurements were collected both above and below the skirt. Outside the cage, DO was recorded at $3 \mathrm{~m}$ depth (Fig. 1). At Fornes, DO was recorded in the cage centre and at 3, 6, 9 and $12 \mathrm{~m}$ depth, as the skirt was $10 \mathrm{~m}$ long. Measurements outside the cage were made at $3 \mathrm{~m}$ depth (Fig. 1). Additional oxygen sensors were deployed at the perimeter at $3 \mathrm{~m}$ depth.

Current speed and direction were recorded using an Aanderaa SeaGuard II Doppler current profiler (DCP) measuring continuously with a sampling frequency of $0.67 \mathrm{~Hz}$ (Fig. 1). Data were averaged and stored every minute. The DCP was attached to an anchoring buoy at both sites pointing downwards with vertical resolution (cell size) set to $1 \mathrm{~m}$. As buoymounted DCPs can experience bias (Mayer et al. 2007), the first depth cell was excluded from the data set.

To measure vertical conductivity and temperature profiles, a SonTek CastAway CTD probe (SonTek/ Xylem) was used inside and outside the cage at both sites (Fig. 1). CTD measurements were obtained manually the afternoon before and the morning after each measurement period. 


\subsection{Statistical analysis}

Analyses were performed in MATLAB v. R2018b. A Kolmogorov-Smirnov test revealed that DO data were not normally distributed in any sensor at either location $(p<0.05)$. To test if there was a significant difference in DO levels inside and outside of the fish cage, the non-parametric Kruskal-Wallis test was applied to data from each location for each night. That is, the data from the sensors at 3, 6, 9 and $12 \mathrm{~m}$ inside the cage at Fornes were compared with those from the sensor at $3 \mathrm{~m}$ outside, while the data from the sensors at 2, 4, 6 and $8 \mathrm{~m}$ at Soløya were compared with those from the sensor at $3 \mathrm{~m}$ depth outside. All recorded data from the relevant periods were included as there were no outliers. When significant differences were detected, a Tukey-Kramer post hoc test was used to determine significant differences between measurements inside and outside the cage.

\section{RESULTS}

At both locations, and for all periods, the KruskalWallis test confirmed that at least 2 of the DO sensors gave measurements that came from different distributions $(p<0.01)$. The Tukey-Kramer post hoc test further determined that there was a significant difference between the sensor outside and those inside $(p<0.01)$ at both locations.

\subsection{Soløya data}

Soløya had no clear tidal pattern and appeared chaotic with relatively low current speed throughout the period, but with some short bursts of $0.2 \mathrm{~m} \mathrm{~s}^{-1}$ in the upper $5 \mathrm{~m}$ (Fig. 2). The chaotic pattern at Soløya is also shown in Fig. 3, which shows the current roses for both locations, where the

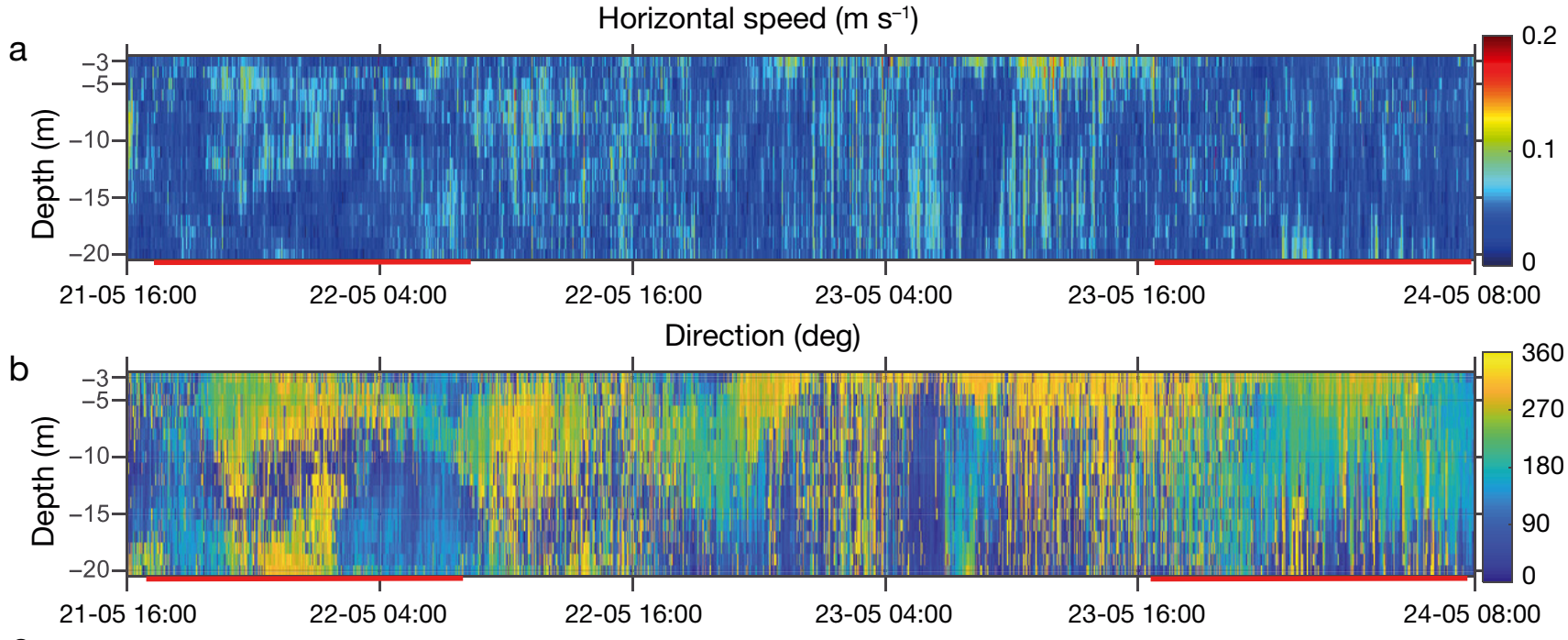

$\mathrm{C}$
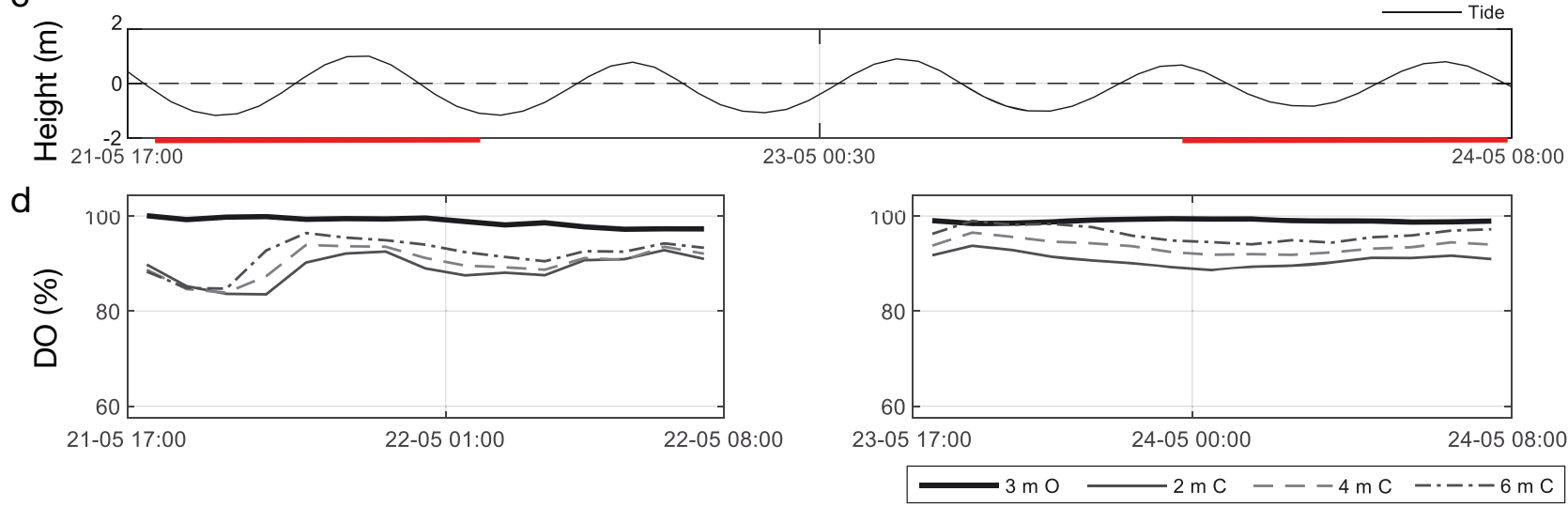

Fig. 2. (a) Current speed and (b) direction at Soløya in the top $20 \mathrm{~m}$ of the water column, measured by the Doppler current profiler (DCP) in position B (see Fig. 1) from 21 to 24 May 2019. The red horizontal line along the $x$-axis indicates the periods where DO measurements were taken. (c) Expected tidal height (thin black line). (d) Hourly median DO for all sensors at Soløya, for the periods marked with red in the graphs above. O: outside; C: centre of the cage 
a

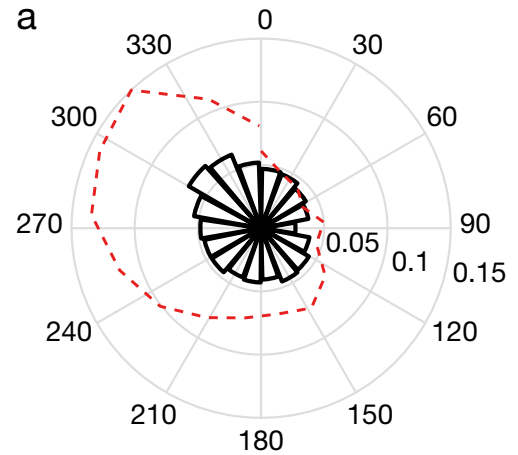

b

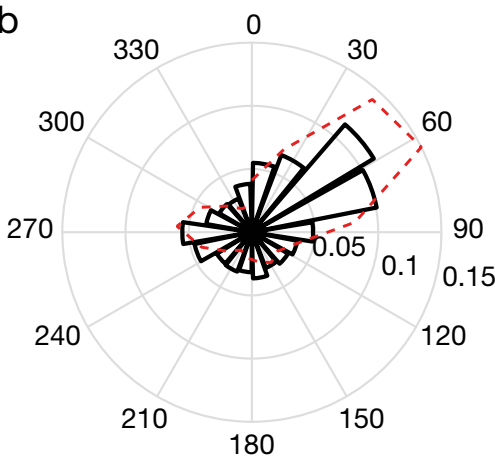

Fig. 3. Current roses showing average current speed and direction measured in the 3rd cell starting at $4 \mathrm{~m}$ depth of the DCP at (a) Soløya and (b) Fornes for the entire period the DCP was deployed. North is $0^{\circ}$, and east is $90^{\circ}$. Directions were sorted into bins of $20^{\circ}$, and average current speed for the given bin is shown in the polarplot. The red dashed line shows the direction that had the largest number of measurements, which was normalized based on the direction that had the largest number of measurements

21-May: 13:13 \& 14:25

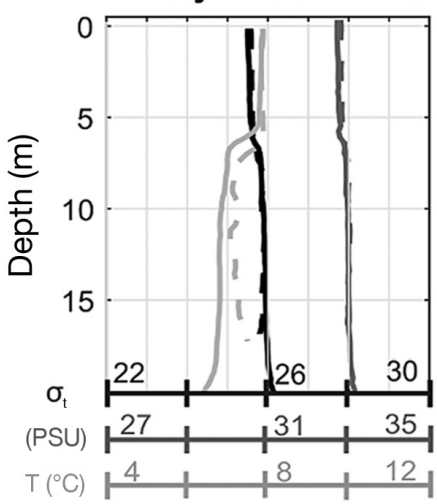

23-May: $16: 19 \& 16: 25$

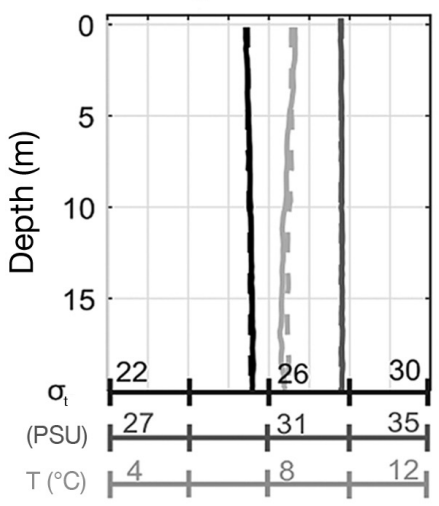

22-May: 09:46 \& 09:50

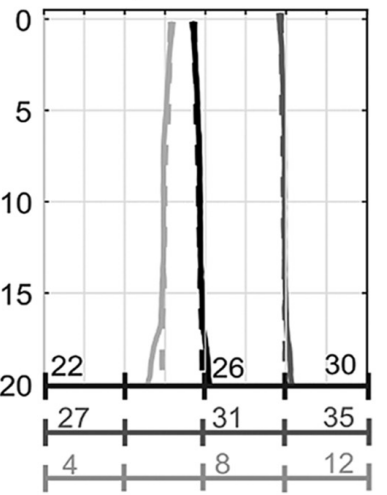

24-May: 08:48 \& 08:52

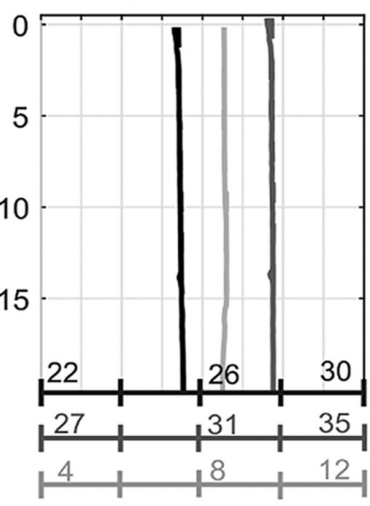

Fig. 4. Water density $\left(\sigma_{t}\right)$, salinity (PSU) and temperature $\left({ }^{\circ} \mathrm{C}\right.$ ) measured by the CTD at Soløya outside the fish cage in position $\mathrm{A}_{2}$ (solid line) (see Fig. 1 for details), and inside the fish cage at position $\mathrm{A}_{1}$ (dashed line). The time stamps above each graph represent the time the measurement was started outside and inside for each date, respectively

direction of the current at Soløya is more diffuse than that at Fornes, which showed a clear main direction.

The water column at Soløya was homogeneous through the study, with the exception of the data gathered on 21 May; here, there was a weak thermocline at $6 \mathrm{~m}$ depth with a difference of $1^{\circ} \mathrm{C}$ between the water over and underneath the stratification (Fig. 4). This was also the only measurement where there appeared to be a slight difference in temperature between inside and outside the cage, with higher temperatures inside (Fig. 4). Except for this measurement, the water column appeared homogeneous and identical inside and outside the cage.

The DO sensors also had temperature sensors; the minimum and maximum temperatures recorded inside the cage were 6.5 and $8.4^{\circ} \mathrm{C}$, respectively. The maximum standard deviation recorded during one of the measurement periods inside the cage was $0.26^{\circ} \mathrm{C}$.

The variability in DO, both outside and inside the cage, was greater during the first night than the second (Fig. 5). According to the Tukey-Kramer post hoc test, all sensors had mean ranks significantly different from

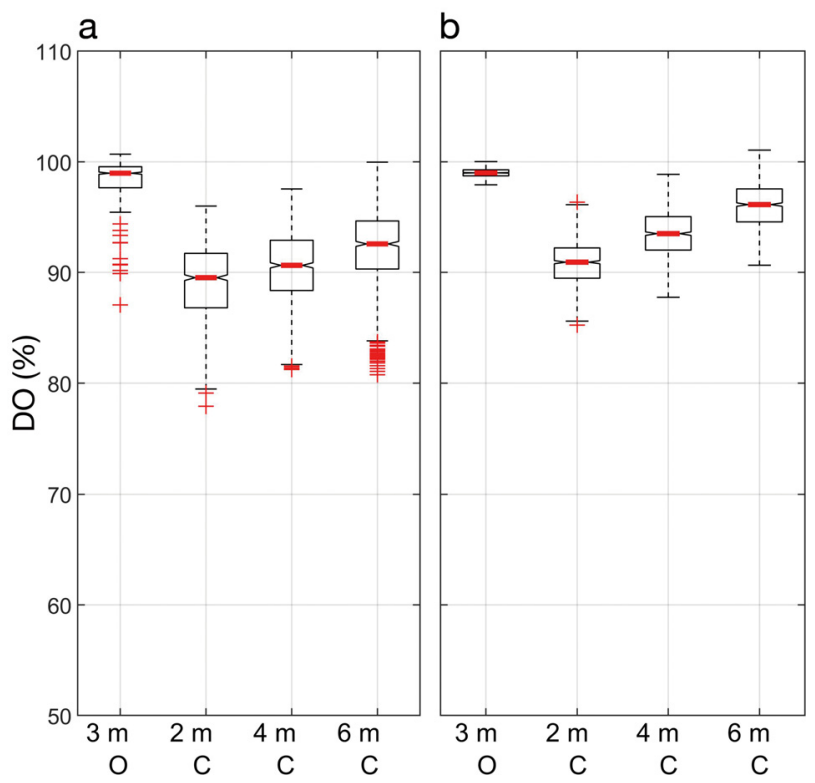

Fig. 5. Boxplot of oxygen levels at Soløya, showing combined oxygen data collected between (a) 21 May 17:00 h and 22 May 08:00 $\mathrm{h}$ and (b) 23 May 17:00 h and 24 May 08:00 h (right). The boxplots show the median DO (red line inside box), the lower edge of the box represents the 1st quartile (Q1) and the upper edge the 3rd quartile (Q3). The whiskers extends to Q1 minus 1.5 times the interquartile range (IQR) and to Q3 + 1.5 IQR. Data outside of the whiskers are measurements that exceed these limits (red crosses). The depth of the sensors is given on the $x$-axis with the positions. O: outside; $\mathrm{C}$ : centre of the cage 
each other $(\mathrm{p}<0.01)$. The lowest recorded DO level was $78 \%$ inside and $87 \%$ outside the cage, while the maximum was $101 \%$ both inside and outside. The hourly medians of DO inside the cage varied together, and there was an increase in DO with depth (Fig. 2).

\subsection{Fornes data}

At Fornes, there was a periodical semi-diurnal tidal pattern with a clear main direction and a maximum current speed of $0.2 \mathrm{~m} \mathrm{~s}^{-1}$ (Figs. $3 \& 6$ ). There was a pycnocline present that broke down gradually over the measurement period. In the first measurement, the relative density $\left(\sigma_{t}\right)$, salinity and temperature inside and outside the cage were identical the entire depth, with a stratification at $8 \mathrm{~m}$ depth (Fig. 7). The temperature varied less than the salinity, hence it was mainly the salinity which influenced the density gradient at Fornes. As the difference between inside and outside increased, the inside of the cage had a higher relative density and higher salinity than the water outside (Fig. 7). On 5 July, the water had become more homogeneous,

a

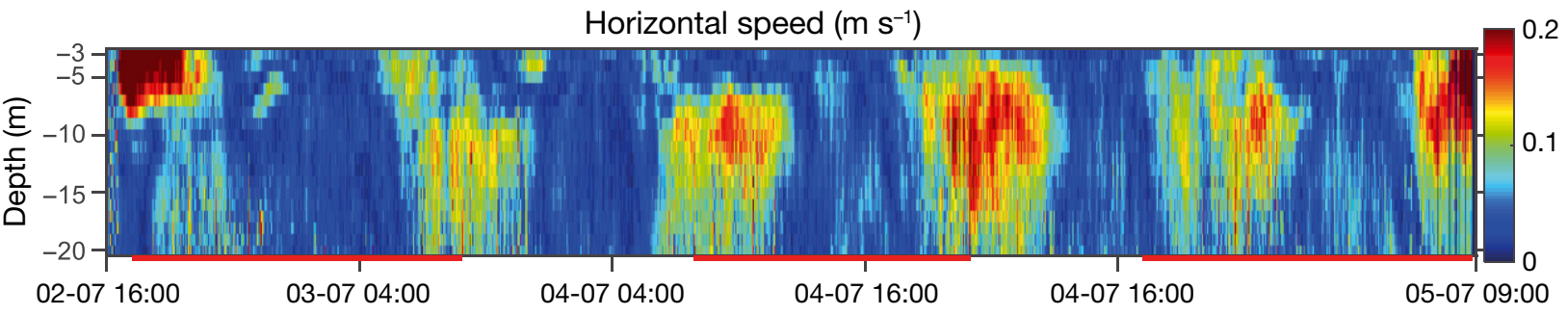

b

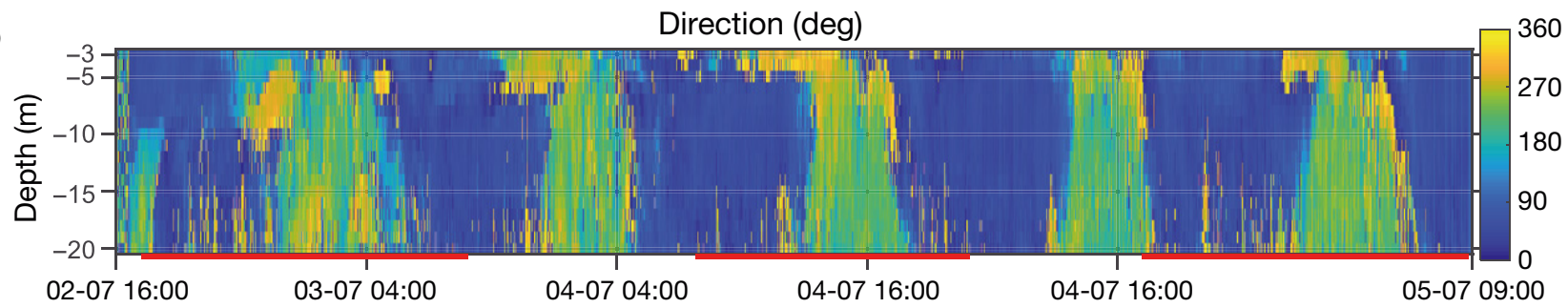

C

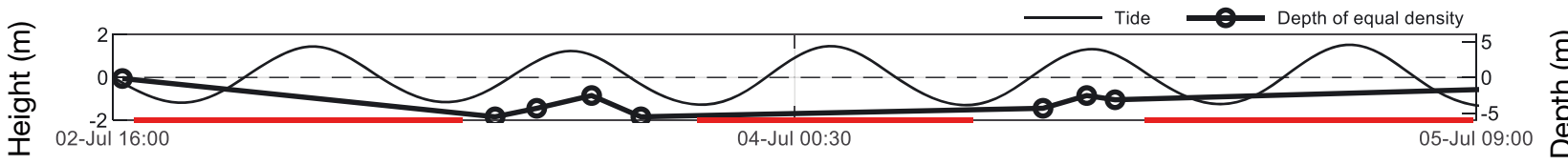

d
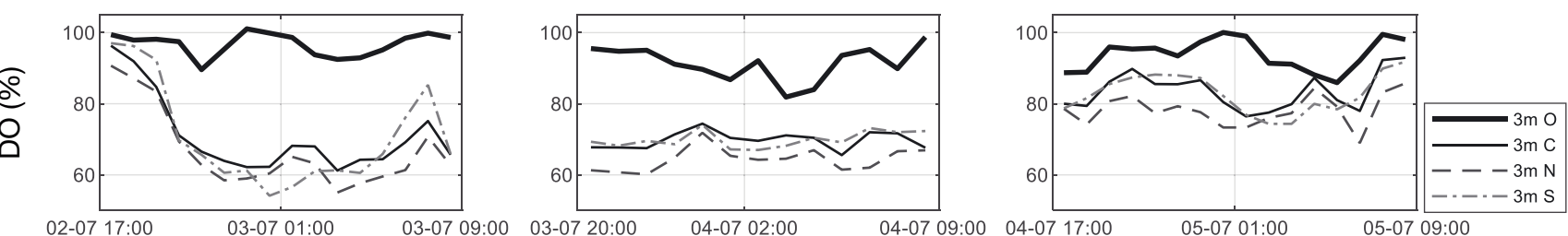

e
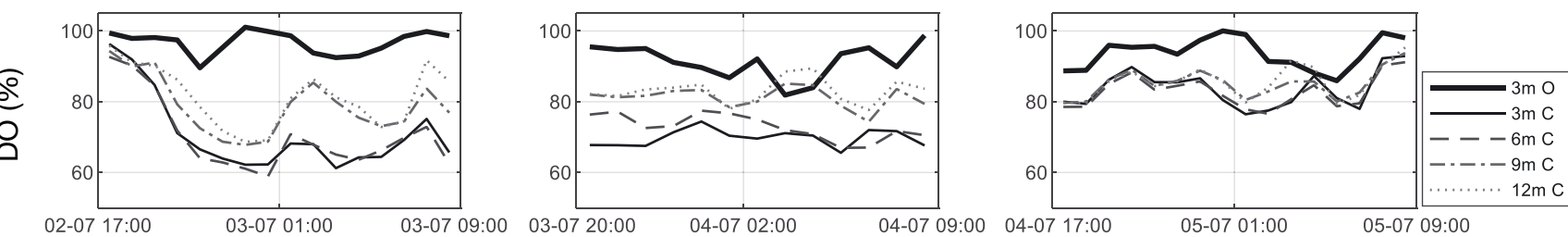

Fig. 6. (a) Current speed and (b) direction at Fornes in the top $20 \mathrm{~m}$ of the water column, measured by the DCP in position B (see Fig. 1) from 02 to 05 July 2019. Note that the measurement at 02 July 16:00 h between 3 and $10 \mathrm{~m}$ is potentially noise from a nearby boat. The red horizontal line along the $x$-axis indicates the period where DO measurements were taken. (c) Expected tidal height (thin black line) and the depth at which the density inside and outside the cage was equal (see Fig. 7 for density graphs); it should be noted that on 3 and 4 July, 2 and 1 additional CTD measurements, respectively, were included which are not represented in Fig. 7, as they were deemed redundant. (d,e) Hourly median DO for all oxygen sensors at Fornes for the periods marked with red. (d) Median for all sensors placed at $3 \mathrm{~m}$ depth, both outside and inside the cage. (e) Median for all sensors placed in the center of the cage, in addition to the one sensor placed outside the cage. O: outside; N: north; $\mathrm{S}$ : south; 
02-Jul: 16:27 \& 16:31
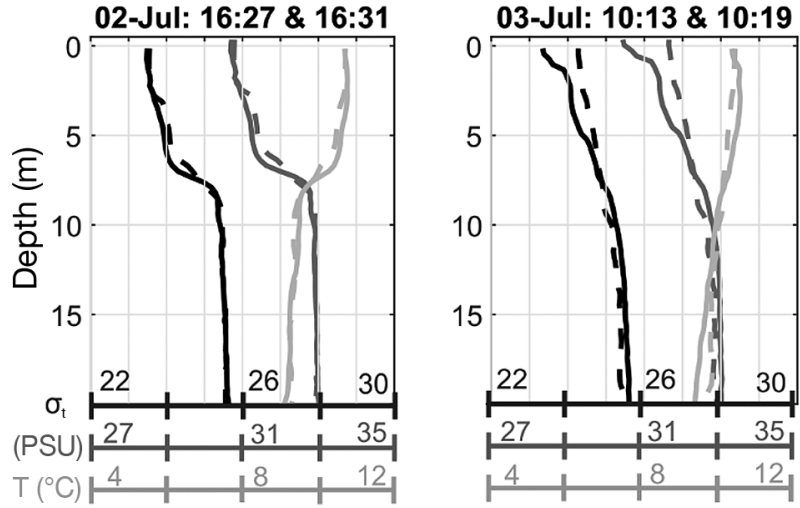

04-Jul: 12:20 \& 12:26

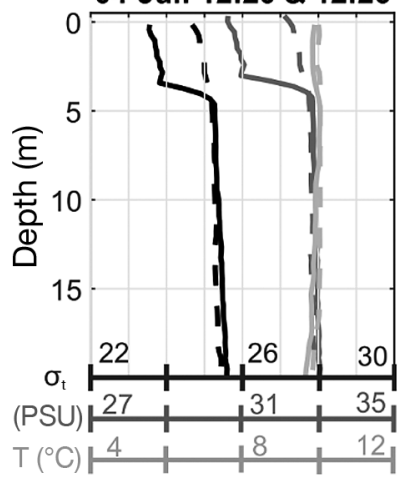

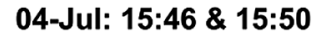

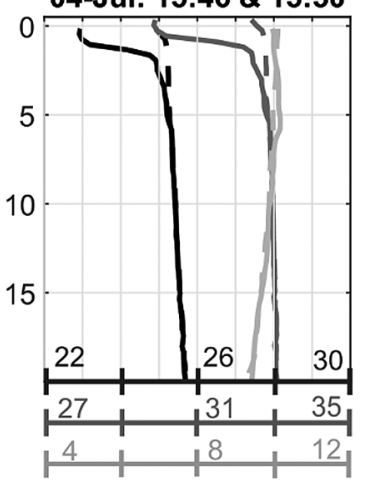

03-Jul: 17:10 \& 17:16

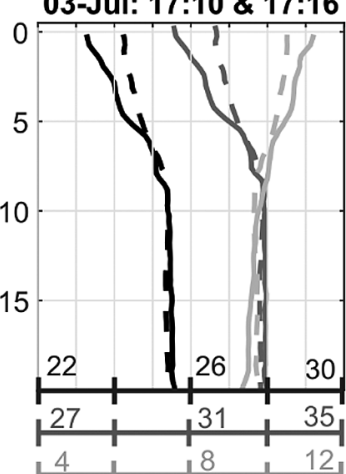

05-Jul: 09:48 \& 09:53

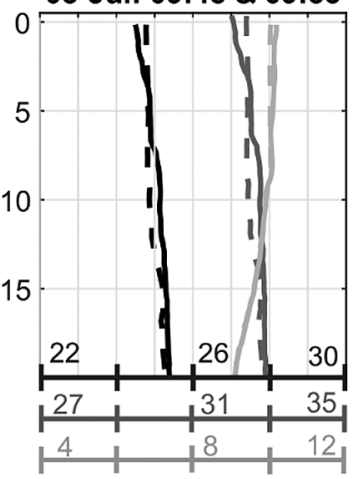

Fig. 7. Water density $\left(\sigma_{t}\right)$, salinity (PSU) and temperature $\left({ }^{\circ} \mathrm{C}\right.$ ) measured by the CTD at Fornes outside the fish cage in position $\mathrm{A}_{2}$ (solid line) (see Fig. 1), and inside the fish cage at position $\mathrm{A}_{1}$ (dashed line). The time stamps above each figure represent the time the measurement was started outside and inside for each date, respectively

with identical measurements inside and outside the cage (Fig. 7). To give an indication of how the density gradient changed with time, the depth at which the difference between the density outside and inside was less than 0.2 is indicated in Fig. 6. During the study period, this depth varied from $0.14 \mathrm{~m}$ on the first day to a maximum of $5.5 \mathrm{~m}$ on 3 July, and back up to $1.6 \mathrm{~m}$ on 5 July (Fig. 6). The minimum and maximum recorded temperatures at Fornes in the DO sensors inside the cage were 9.0 and $10.9^{\circ} \mathrm{C}$, with a maximum standard deviation of $0.3^{\circ} \mathrm{C}$ in one of the sensors during one of the measurement periods.

There was a larger variance in DO levels at Fornes than at Soløya, with a minimum of $52 \%$ and a maximum of $98 \%$ DO inside the fish cage, and a minimum of $76 \%$ and maximum of $102 \%$ DO outside the fish cage (Fig. 8). There was some variation between the DO levels recorded at $3 \mathrm{~m}$ depth, with the DO in position $\mathrm{N}$ recording the lowest hourly medians (Fig. 6). The mean rank for this sensor was significantly different from all other sensors each night (Tukey-Kramer post hoc, $p>0.05)$. The first and second nights, there was little difference between the sensors at 3 and $6 \mathrm{~m}$ depth and between the sensors at 9 and $12 \mathrm{~m}$ depth. The first night, the sensor at $6 \mathrm{~m}$ depth was

not significantly different from the sensors at $3 \mathrm{~m}$ in the centre and south in the cage (Tukey-Kramer post hoc, p > 0.05). On the second night, only the sensors at $3 \mathrm{~m}$ positioned in the centre and south were not significantly different $(p>0.05)$. The third night, variation between depths disappeared inside the cage, with nearly similar DO recorded on all sensors, and the sensors at 3 and $6 \mathrm{~m}$ in the centre were not significantly different, nor were the sensors at 9 and $12 \mathrm{~m}(\mathrm{p}>0.05)$. As with the DO at Soløya, there was an increase in DO with depth (Figs. 6 and 8).

\section{DISCUSSION}

Comparing the effect of the permeable and nonpermeable lice skirt on the internal environment is of limited value due to the differences in topography, hydrography and current flow pattern at the 2 study sites. However, independent of skirt type, the DO improved at both locations with depth inside the cage (Figs. 5 \& 8), and both sites had a significant difference in DO between the inside and outside of the cage $(\mathrm{p}<0.01$, Tukey-Kramer post hoc test), with a lower median DO inside the cage. 


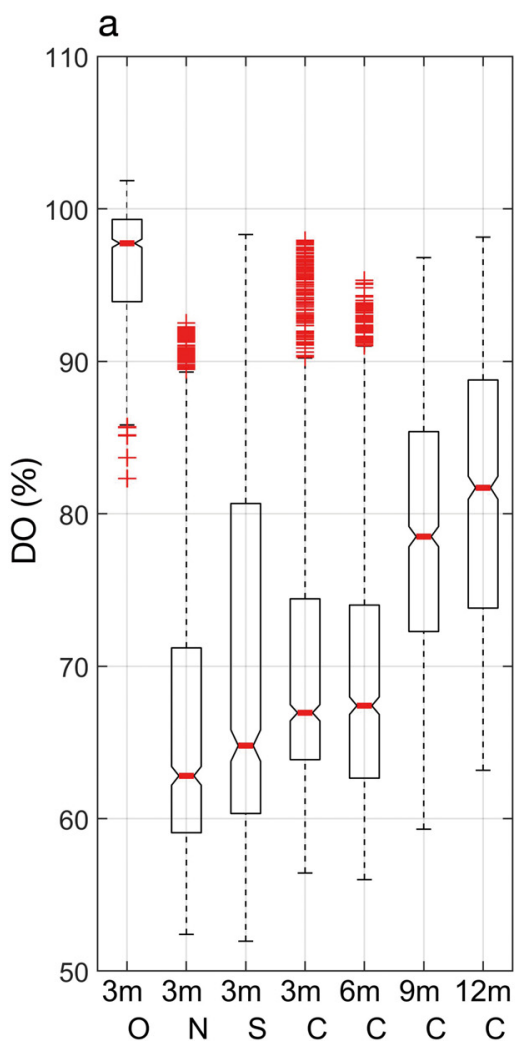

b

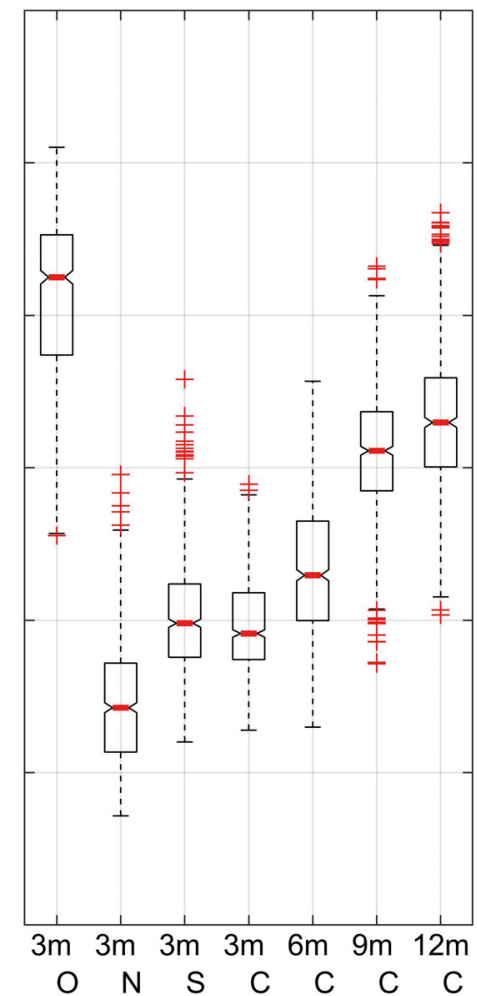

C

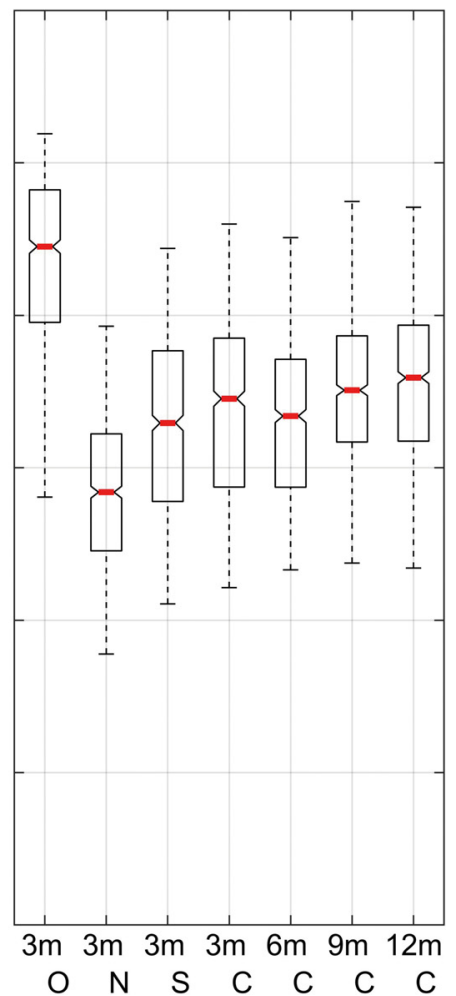

Fig. 8. Boxplot representations of oxygen levels at Fornes, showing the combined oxygen data collected between (a) 02 July 17:00 h and 03 July 09:00 h, (b) 03 July 20:00 h and 04 July 09:00 h and (c) 04 July 17:00 h and 05 July 09:00 h. The boxplots show the median DO (red line inside box), the lower edge of the box represents the 1st quartile (Q1) and the upper edge the 3rd quartile (Q3). The whiskers extends to Q1 minus 1.5 times the interquartile range (IQR), and to Q3 + 1.5 IQR. Data outside of the whiskers are measurements that exceed these limits (red crosses). The depth of the sensors is given on the $x$-axis with their positions. O: outside; $\mathrm{N}$ : north; $\mathrm{S}$ : south; $\mathrm{C}$ : centre of the cage

\subsection{Soløya}

It was initially assumed that Soløya would have lower DO levels inside the cage than Fornes, as Soløya was equipped with a non-permeable skirt, while Fornes had a permeable one. However, this was not the case; throughout the measurement period, DO was higher at Soløya.

The current at Soløya appeared weak throughout most of the study period, with speeds below $7 \mathrm{~cm} \mathrm{~s}^{-1}$, and did not show a tidal pattern (Fig. 2). The direction of the current was diffuse, compared to Fornes, with a dominant direction towards the northwest and west (Fig. 3). Soløya is placed in a strait with several small islands to the south, and to the north there is a very narrow strait that leads out to Selfjorden and then to the open Norwegian Sea. The larger variance seen in direction at Soløya could be explained by the local topography and the position of the farm.

This dominant current direction of northwest meant that the cages south of the studied cage could have had a shielding effect on the current flow through the cage and hence DO levels. However, as evidenced by the consistently high DO both inside and outside the cage, the shielding effect was negligible in this instance.

Vertical stratification of the water column, as occurs when a pycnocline is present, is known to inhibit vertical mixing (Imberger 2013). The water column at Soløya was non-stratified with near identical characteristics inside and outside the cage except the first measurement, which showed signs of a weak pycnocline (Fig. 4). The lack of stratification meant that there was no inhibition of vertical mixing at Soløya, and the good DO conditions could be a result of good vertical mixing in the water column.

DO gradients in unshielded cages are reported to increase with depth at some sites (Johansson et al. 2007, Solstorm et al. 2018), while others see a decrease with depth (Johansson et al. 2007, Oldham et al. 2018). The DO at Soløya was lower inside the cage than outside for most of the study period, and the DO had a gradual improvement with depth, with an almost linear relationship (Fig. 5). Increases in DO 
with depth are observed in studies using both nonpermeable skirts (Stien et al. 2012) and permeable skirts (Stien et al. 2018), similar to those used in the present study. It is therefore likely that the increase with depth when using shielding skirts is due to the shielding skirt itself.

If the homogeneous water at Soløya is caused by vertical mixing, it is uncertain whether the skirt is actually effective in preventing lice from entering the cage, as the vertical mixing could result in the lice being pushed further down in the water column, below the skirt and into the cage. The skirt length of $5 \mathrm{~m}$ may not be sufficient if that is the case. However, more environmental data and lice counts are needed to verify this.

\subsection{Fornes}

The current at Fornes had a clear, dominant southeast-northwest direction and tidal component demonstrated by the semi-diurnal pattern observed in the current speed and direction (Fig. 6). It should be noted that the dominant direction of the current resulted in the DCP's position relative to the cage to be either upstream or downstream of the cage, depending on the phase of the tidal cycle. When upstream of the cage, the DCP recorded the incoming unobstructed current, while downstream measurements were affected by the speed reduction and turbulence caused by the cage structure (Klebert et al. 2015). When the current was moving southwards, the current speed was therefore higher than recorded.

DO at Fornes had a greater variability with a minimum of $52 \%$, and DO levels improved with depth (Figs. 6 \& 8). The variability seen between the sensors at $3 \mathrm{~m}$ depth can be explained by the current direction and position of the sensors (Fig. 6). As the current travels through the cage, a reduction in speed is expected (Klebert et al. 2015), which can result in a lower water exchange downstream in the cage, as observed by Solstorm et al. (2018). It is therefore possible that the reason that the sensors in positions $\mathrm{N}$ and $\mathrm{S}$ had a lower median than in the centre of the cage on the first and third nights was due to the current turning and flowing in both directions during the measurement periods (Figs. 6 and 8). On the second night, the stratification appears to have influenced the current in the upper $5 \mathrm{~m}$, which appears to be moving mainly towards the north and north-northwest (Fig. 6), explaining why the lowest median current was recorded by the sensor in position N (Fig. 8).
The improvement in DO with depth was not linear at Fornes. The sensors at 3 and $6 \mathrm{~m}$ were more similar than those at 9 and $12 \mathrm{~m}$, indicating that the skirt had a direct impact on the sensors at 3 and $6 \mathrm{~m}$, but not at $9 \mathrm{~m}$ depth. This is plausible as the skirt, which was $10 \mathrm{~m}$ long, was installed as a cylinder around the conically shaped net. Moderate currents can result in the skirt being pushed into the net and lifted upwards (Lien et al. 2014); it is therefore not unlikely that the sensor at $9 \mathrm{~m}$ was not fully shielded, explaining why it is more similar to the sensor at $12 \mathrm{~m}$ than to that at $6 \mathrm{~m}$ (Figs. $6 \& 8$ ).

However, this grouping of the sensors was not always clear. For instance, during the first couple of hours and the last night, all sensors recorded similar DO levels (Fig. 6). The grouping first appeared as the DO dropped at all depths the first night. It is uncertain if this drop also occurred outside of the cage in deeper layers, as the reference sensor was at $3 \mathrm{~m}$ depth, and prior to this drop, a pycnocline was recorded at $8 \mathrm{~m}$ depth (Fig. 7). A potential cause for the drop is therefore that the water below this pycnocline had lower DO, and it was this water that moved into the cage. Another possibility is that the DO drop occurred due to the high stocking density of $20 \mathrm{~kg} \mathrm{~m}^{-3}$ or an increase in fish activity; however, there were no data recorded regarding the vertical position of the fish. The specific reason for the steep drop the first night cannot be interpreted from the data recorded.

It should be noted that other experiments applying the same type of permeable skirt as used in this study saw no impact on the welfare status of the salmon (Stien et al. 2018, Bui et al. 2020). When using similar skirt with $10 \mathrm{~m}$ length, the minimum DO inside the cage was $70 \%$ during a 3-mo period (Stien et al. 2018), indicating that the length of the skirt is not the main reason for the low DO inside the cage. A possible reason for the higher DO in Stien et al. (2018) compared with the present study could be the low stocking density of $<10 \mathrm{~kg} \mathrm{~m}^{-3}$. However, the difference in stocking density does not explain the observed temporal variability in DO.

It is uncertain whether the low DO levels recorded in this study had any negative effect on the fish. Moderate hypoxia of $50 \%$ DO in water of $16^{\circ} \mathrm{C}$ significantly reduces aerobic capacity and swimming performance of Atlantic salmon Salmo salar (Oldham et al. 2019). The temperature at Fornes never exceeded $11^{\circ} \mathrm{C}$, and as required DO increases with temperature, it is uncertain whether the reduced DO posed any real threat to fish welfare or growth. Furthermore, the observations were made over a relatively short period, and as DO was higher at other 
locations in the cage (Fig. 6), the fish had the opportunity to avoid the areas with low DO. However, it should be noted that avoidance behaviour is documented for DO $<35 \%$, but not for sub-optimal waters with $\mathrm{DO}<60 \%$, indicating that DO is not a primary driver of behaviour (Oldham et al. 2017, Stehfest et al. 2017).

An explanation for the variation in DO through the study is the hydrography. The current flow at Fornes showed periods where the current speed was faster at deeper layers, indicating a stratification in the water column (Fig. 6). As discussed previously, pycnoclines and haloclines have been observed to impact the DO inside fish cages (Johansson et al. 2006, Stien et al. 2012). The first CTD measurement at Fornes revealed a clear pycnocline, with nearly identical density recorded inside and outside the cage (Fig. 7). The hourly median DO levels inside the cage were nearly equal to DO outside the cage for the first couple of hours (Fig. 6). There was then a sudden drop in DO, which remained throughout the night. During the second and third days, there was a difference in density in the top $6 \mathrm{~m}$ of the water column (Fig. 7). The depths at which the density outside and inside the cage were approximately equal varied throughout the period (Fig. 6), and it appeared that as the depth of equal density moved upwards, the DO levels inside the fish cage improved (Figs. 6 \& 8). It should be noted that on 4 July, the stratification had moved up to roughly $2 \mathrm{~m}$, hence the pycnocline would be at a higher depth level than the DO sensor at $3 \mathrm{~m}$ depth. There are no data for the DO above this depth, and there is a possibility that the DO was lower in this area.

The presence of a density gradient may have influenced the water exchange rate and water flow through the permeable skirt. For the cage at Fornes, water exchange could occur in 2 ways, either from the water passing through the skirt or by the water being pressed down along the skirt and into the cage (Lien \& Høy 2011, Lien et al. 2015). When a pycnocline is present and remains above the skirt depth, it could result in the water above the pycnocline being prevented from moving down along the skirt and into the fish cage. However, as the pycnocline moves higher up along the skirt, more of the water below is free to move underneath the skirt and into the cage.

The water above and below the pycnocline is free to pass through the permeable skirt, but how much water actually passed through the permeable skirt was not verified in this study. However, the periods with difference in water density between the inside and outside suggest that the skirt rerouted a large portion of the upper water column around the fish cage and there was not enough water that passed through the skirt to replace the water with low DO inside. This could be due to the size of the cage (as larger cages are reported to have lower DO levels; Oldham et al. 2018), the density of fish, or fouling of the skirt and net, which can reduce water flow (Gansel et al. 2015). It is also possible that the higher density inside the cage created a blocking effect of the water. It has been theorized that the swimming behaviour of the fish can attenuate and redirect the water current (Johansson et al. 2007), and that when the fish are swimming in a torus shape, they produce an area with high pressure inside the cage, which results in the water being pressed outwards (Gansel et al. 2014). The higher density seen in the present study could have resulted in a similar result, with the higher-density water on the inside forcing more of the water around the cage as it blocked the lowerdensity water from passing through the permeable skirt. This could explain some of the variation seen at Fornes, but more research is needed on this possible effect.

\section{CONCLUSIONS}

To prevent salmon lice Lepeophtheirus salmonis infestations, shielding skirts were used to attempt to reroute the upper layer of the water column around the cage. The effect shielding skirts have on the internal environment of the sea-cage, particularly the DO concentration, varied between sites. In this study, 2 hydrographically different sites were studied. The DO improved with depth at both sites; however, the impact of the shielding skirt varied. The DO levels were higher at Soløya, which was a nonstratified site, while the stratified site Fornes had larger temporal and spatial variance in DO, and this variation appeared to co-occur with the presence and depth of a pycnocline. The local variations exemplified in this study demonstrate the complex relationship between DO, current and stratifications when shielding skirts are used. To verify and document the interaction between shielding skirts, pycnoclines and current flow, and how this influences lice prevention, more data are needed either by studying the underlying mechanisms in a more controlled environment or from long-term studies.

Acknowledgements. This study is part of the project 'Shielding skirt as a method for prevention and control of salmon lice infestation-improving knowledge about environmen- 
tal conditions for increase in efficiency and reduction of risk (SKJERMTEK)' (project no. 901396) funded by The Norwegian Seafood Research Fund (FHF). K.E.J. received funding from the RACE research grant program funded by SINTEF Ocean. We are thankful for access to equipment from SINTEF ACE, and to Ellingsen Seafood AS and Nordlaks Oppdrett AS for access to their sites and the help received from their on-site employees.

\section{LITERATURE CITED}

Barrett LT, Oppedal F, Robinson N, Dempster T (2020) Prevention not cure: a review of methods to avoid sea lice infestations in salmon aquaculture. Rev Aquacult 12: 2527-2543

* Bricknell IR, Dalesman SJ, O'Shea B, Pert CC, Luntz AJM (2006) Effect of environmental salinity on sea lice Lepeophtheirus salmonis settlement success. Dis Aquat Org 71:201-212

Bui S, Stien LH, Nilsson J, Trengereid H, Oppedal F (2020) Efficiency and welfare impact of long-term simultaneous in situ management strategies for salmon louse reduction in commercial sea-cages. Aquaculture 520:734934

Crosbie T, Wright DW, Oppedal F, Johnsen IA, Samsing F, Dempster T (2019) Effects of step salinity gradients on salmon lice larvae behaviour and dispersal. Aquacult Environ Interact 11:181-190

Crosbie T, Wright DW, Oppedal F, Dalvin S, Myksvoll MS, Dempster T (2020) Impact of thermoclines on the vertical distribution of salmon lice larvae. Aquacult Environ Interact 12:1-10

Frank K, Gansel LC, Lien AM, Birkevold J (2015) Effects of a shielding skirt for prevention of sea lice on the flow past stocked salmon fish cages. J Offshore Mech Arctic Eng 137:011201

Gansel LC, Rackebrandt S, Oppedal F, McClimans TA (2014) Flow fields inside stocked fish cages and the near environment. J Offshore Mech Arctic Eng 136:031201

Gansel LC, Plew DR, Endresen PC, Olsen AI, Misimi E, Guenther J, Jensen $\varnothing$ (2015) Drag of clean and fouled net panels-measurements and parameterization of fouling. PLOS ONE 10:e0131051

Geitung L, Oppedal F, Stien LH, Dempster T, Karlsbakk E, Nola V, Wright DW (2019) Snorkel sea-cage technology decreases salmon louse infestation by $75 \%$ in a full-cycle commercial test. Int J Parasitol 49:843-846

Grøntvedt RN, Kristoffersen AB (2015) Permaskjørt kan redusere påslag av lakselus-analyse av feltdata. Delrapport Permaskjørt-prosjektet A5. Report 2. Norwegian Veterinary Institute, Oslo, Norway

Grøntvedt RN, Kristoffersen AB, Jansen PA (2018) Reduced exposure of farmed salmon to salmon louse (Lepeophtheirus salmonis L.) infestation by use of plankton nets: Estimating the shielding effect. Aquaculture 495: 865-872

Heuch PA, Parsons A, Boxaspen K (1995) Diel vertical migration: a possible host-finding mechanism in salmon louse (Lepeophtheirus salmonis) copepodids? Can J Fish Aquat Sci 52:681-689

Hevrøy EM, Boxaspen K, Oppedal F, Taranger GL, Holm JC (2003) The effect of artificial light treatment and depth on the infestation of the sea louse Lepeophtheirus salmonis on Atlantic salmon (Salmo salar L.) culture. Aquaculture 220:1-14
Huse I, Holm JC (1993) Vertical distribution of Atlantic salmon (Salmo salar) as a function of illumination. J Fish Biol 43:147-156

Imberger J (2013) Environmental fluid dynamics: flow processes, scaling, equations of motion, and solutions to environmental flows. Academic Press, Waltham, MA

Kohansson D, Ruohonen K, Kiessling A, Oppedal F, Stiansen JE, Kelly M, Juell JE (2006) Effect of environmental factors on swimming depth preferences of Atlantic salmon (Salmo salar L.) and temporal and spatial variations in oxygen levels in sea-cages at a fjord site. Aquaculture 254:594-605

Johansson D, Juell JE, Oppedal F, Stiansen JE, Ruohonen K (2007) The influence of the pycnocline and cage resistance on current flow, oxygen flux and swimming behaviour of Atlantic salmon (Salmo salar L.) in production cages. Aquaculture 265:271-287

Klebert P, Su B (2020) Turbulence and flow field alterations inside a fish sea cage and its wake. Appl Ocean Res 98: 102113

Klebert P, Lader P, Gansel L, Oppedal F (2013) Hydrodynamic interactions on net panel and aquaculture fish cages: a review. Ocean Eng 58:260-274

Klebert P, Patursson Ø, Endresen PC, Rundtop P, Birkevold J, Rasmussen HW (2015) Three-dimensional deformation of a large circular flexible sea-cage in high currents: Field experiment and modeling. Ocean Eng 104: 511-520

Lien AM, Høy E (2011) Skjørt for Skjerming mot lus i Laksemerd. Rep No A19396, SINTEF Fiskeri og Havbruk, Trondheim

*Lien AM, Volent Z, Jensen Ø, Lader P, Sunde LM (2014) Shielding skirt for prevention of salmon lice (Lepeophtheirus salmonis) infestation on Atlantic salmon (Salmo salar L.) in cages - a scaled model experimental study on net and skirt deformation, total mooring load, and currents. Aquacult Eng 58:1-10

Lien AM, Stien LH, Grøntvedt R, Frank K (2015) Permanent skjørt for redusering av luspåslag på laks. Rep No A26790, SINTEF Fiskeri og Havbruk

* Mayer DA, Virmani JI, Weisberg RH (2007) Velocity comparisons from upward and downward acoustic Doppler current profilers on the West Florida Shelf. J Atmos Ocean Technol 24:1950-1960

Næs M, Heuch PA, Mathisen R (2012) Bruk av 'luseskjørt' for å redusere påslag av lakselus Lepeophtheirus salmonis (Krøyer) på oppdrettslaks. Vesterålen Fiskehelsetjeneste, Sortland

Oldham T, Dempster T, Fosse JO, Oppedal F (2017) Oxygen gradients affect behaviour of caged Atlantic salmon Salmo salar. Aquacult Environ Interact 9:145-153

Oldham T, Oppedal F, Dempster T (2018) Cage size affects dissolved oxygen distribution in salmon aquaculture. Aquacult Environ Interact 10:149-156

F Oldham T, Nowak B, Hvas M, Oppedal F (2019) Metabolic and functional impacts of hypoxia vary with size in Atlantic salmon. Comp Biochem Physiol A Mol Integr Physiol 231:30-38

O Oppedal F, Samsing F, Dempster T, Wright DW, Bui S, Stien LH (2017) Sea lice infestation levels decrease with deeper 'snorkel' barriers in Atlantic salmon sea-cages. Pest Manag Sci 73:1935-1943

* Rasmussen HW, Patursson Ø, Simonsen K (2015) Visualisation of the wake behind fish farming sea-cages. Aquacult Eng 64:25-31 
Remen M, Oppedal F, Imsland AK, Olsen RE, Torgersen T (2013) Hypoxia tolerance thresholds for post-smolt Atlantic salmon: dependency of temperature and hypoxia acclimation. Aquaculture 416-417:41-47

Remen M, Aas TS, Vågseth T, Torgersen T, Olsen RE, Imsland A, Oppedal F (2014) Production performance of Atlantic salmon (Salmo salar L.) postsmolts in cyclic hypoxia, and following compensatory growth. Aquacult Res 45:1355-1366

Remen M, Sievers M, Torgersen T, Oppedal F (2016) The oxygen threshold for maximal feed intake of Atlantic salmon post-smolts is highly temperature-dependent. Aquaculture 464:582-592

Solstorm D, Oldham T, Solstorm F, Klebert P, Stien LH, Vågseth T, Oppedal F (2018) Dissolved oxygen variability in a commercial sea-cage exposes farmed Atlantic salmon to growth limiting conditions. Aquaculture 486:122-129

Editorial responsibility: Tim Dempster, Melbourne, Victoria, Australia
Stehfest KM, Carter CG, McAllister JD, Ross JD, Semmens JM (2017) Response of Atlantic salmon Salmo salar to temperature and dissolved oxygen extremes established using animal-borne environmental sensors. Sci Rep 7: 4545

Stien LH, Nilsson J, Hevrøy EM, Oppedal F, Kristiansen TS, Lien AM, Folkedal O (2012) Skirt around a salmon seacage to reduce infestation of salmon lice resulted in low oxygen levels. Aquacult Eng 51:21-25

Stien LH, Lind MB, Oppedal F, Wright DW, Seternes T (2018) Skirts on salmon production cages reduced salmon lice infestations without affecting fish welfare. Aquaculture 490:281-287

Wildish D, Keizer P, Wilson A, Martin J (1993) Seasonal changes of dissolved oxygen and plant nutrients in seawater near salmonid net pens in the macrotidal Bay of Fundy. Can J Fish Aquat Sci 50:303-311

Submitted: September 1, 2020; Accepted: October 19, 2020 Proofs received from author(s): December 5, 2020 